\title{
MAXILLOFACIAL INJURIES IN A GROUP OF BRAZILIAN SUBJECTS UNDER 18 YEARS OF AGE
}

\author{
Rafaela SCARIOT ${ }^{1}$, Ingrid Araújo de OLIVEIRA ${ }^{1}$, Luis Augusto PASSERI ${ }^{2}$, \\ Nelson Luis Barbosa REBELLATO ${ }^{3}$, Paulo Roberto MÜLLER ${ }^{3}$
}

1- DDS, Resident of Oral and Maxillofacial Surgery, Federal University of Paraná, Curitiba,PR, Brazil.

2- DDS, MS, PhD, Professor, Division of Oral and Maxillofacial Surgery, Dental School of Piracicaba, and Division of Plastic Surgery, School of Medical Sciences, State University of Campinas, Piracicaba, SP, Brazil.

3- DDS, MS, PhD, Professor of Oral and Maxillofacial Surgery, Federal University of Paraná, Curitiba,PR, Brazil.

Corresponding address: Rafaela Scariot - Dr. Brasílio Vicente de Castro, 320, Ap 403 - Campo Comprido - 81200-340 - Curitiba - PR - Brazil.

Phone: 0554132859394 - e-mail: rafaela scariot@yahoo.com.br

Received: May 27, 2008 - Modification: August 31, 2008 - Accepted: October 7, 2008

\begin{abstract}
$O$

bjective: The purpose of this study was to perform a clinical retrospective analysis of the etiology, incidence and treatment of selected oral and maxillofacial injuries in Brazilian children and adolescents. Materials and Methods: This study was conducted during a 14-year period between 1986 and 2000. All patients were admitted to Hospital XV in the city of Curitiba, State of Paraná. Age, gender, monthly distribution, etiology, soft injuries, associated injuries, site of fractures and methods of treatment were reviewed. Results: Of the total of 350 patients of all ages treated for facial injuries, $29.42 \%$ were within the age range of the study $(0$ to 18 years). Mean age was 10.61 . Of the patients, $63.1 \%$ were male. The most common cause of injury was accidental falls (37.87\%), followed by bicycle and motorcycle accidents $(21.36 \%)$. Of the 103 patients, $88.34 \%$ had single injuries. Mandibular fractures were the most common and the condylar region was particularly affected. Conclusion: Facial trauma is a relatively common occurrence in children. The study indicates that fractures in children and adolescents differ quite considerably from an adult population.
\end{abstract}

Key words: Facial injury. Dental trauma. Fracture. Children. Adolescents.

\section{INTRODUCTION}

Incidence of trauma in pediatric and adolescent populations is much less than the in adult population. Fractures of the facial skeleton are uncommon in childhood in comparison with other bones of the body ${ }^{1}$.

Many factors make this age group ( 0 to 18 years) different, such as: bone elasticity, deciduous crown shape, possible incomplete eruption of permanent teeth, deciduous teeth either present in a small number or having their roots resorbed, relatively small-sized face, extent of the paranasal sinus pneumatization, growth process in the young bone ${ }^{7}$, greater craniomaxillofacial mass to body ratio ${ }^{9}$, and others.

The etiology of maxillofacial fractures differs from one country to another because of social, cultural and environmental factors. The main causes worldwide are road traffic accidents, fights, falls and sport injuries. Interpretation of these surveys is difficult because there was also variation in the classification of injured that were used.

Specific investigations of facial injuries have been undertaken in childhood in Scotland ${ }^{1}$, Nigeria ${ }^{7}$, Jordanian ${ }^{9}$,

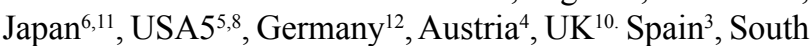
African $^{2}$, and others. Sample sizes have ranged from 26 to
389 and ages have varied between 0 and 19 years.

Pediatric maxillofacial fractures are managed according to the same basic principles applied in adult fractures. However because of the specific aspects to the pediatric dentition and the anatomical differences, it is recommended to perform the treatment considering the age group ${ }^{11}$. The purposes of this study were to estimate the prevalence, to look specifically at nature and etiology of the injuries of the facial skeleton, to analyze the location of fractures, methods of treatment and results from a Brazilian center and compare the results with published data from countries. The term adolescents will refer to patients with 18 years of age or younger, and children from birth to 13 years of age.

\section{Patients and Methods}

This study includes data of patients aged 18 years or younger who were treated at the Emergency Service of Hospital XV, at the city of Curitiba, State of Paraná, from 1986 to 2000. It is necessary to explain that the Emergency Service is not considered a municipal/public reference to trauma patients. The city of Curitiba offers to population the SIATE (Emergency and Trauma Attending Integrated System). SIATE offers first care in the site of accident and 
the injured people are usually referred to municipal emergency rooms.

The patients' records were reviewed and analyzed according to age at the time of injury and gender distribution, monthly and daily distribution, cause of injury and soft injuries, single or multiple injuries, location of fractures, treatment and results of them. The sample was divided into three groups to compare the variables in different age groups. Group A comprised patients aged 0 to 6 years, group B, patients aged 7 to 12 years and group $C$, patients aged 13 to 18 years.

The fractures were evaluated according to location (Table 1). Long-term followed-up was performed on most patients by recall survey.

\section{RESULTS}

From January 1, 1986 to December 31, 2000, 103 patients, children and adolescents, aged 18 years or younger, with 133 different types of maxillofacial fractures were evaluated.

\section{Age and Gender Distribution}

Patient age at the time of the injury ranged from 0 to 18 years, with a mean age of 10.61 . Only $22.3 \%$ of patients were aged between 0 to 6 years (Group A). The most of the cases (Group B: $38.85 \%$ and Group C: $38.85 \%$ ) were between the ages to 7 to 18 years. Most patients were male $(63.1 \%)$, with a male-to-female ratio of approximately $2: 1$.

\section{Etiology}

The most common cause of fractures in our series was accidental falls. This represented $37.87 \%$ (39 patients) in all groups. Bicycle/motorcycle accidents were the cause in $21.36 \%$ of the cases (22 patients). Other less frequent causes were road traffic accidents, fights and sport injuries. The cause injuries varied according the age group. The most common cause of fractures in Group A and in Group B was falls. In group $\mathrm{C}$, the most common cause of mandibular fractures was fight/physical assaults, being characteristic of this age group. Fights involved most predominantly men $(93.4 \%)$ while road traffic accidents involved most frequently women $(56.25 \%)$.

The causes of injury are listed in Table 2 .

\section{Monthly Distribution}

Of 103 patients, 29 patients came to hospital between December and February, 27 between March and May, 23 between June and August and 24 between September and November.

\section{Concomitant injuries}

Children and adolescents with craniomaxillofacial trauma sustained $12(11.66 \%)$ associated injuries, mainly cranial injuries $(42,86 \%)$ with or without operative intervention, inferior extremities $(28,59 \%)$, superior extremities $(14,28 \%)$, and others.

\section{Soft Tissue Injuries}

From a total of 103 patients who had 133 facial bone fractures (also in combination with alveolar fracture), $27.18 \%$ had soft tissue injuries. Among this injuries, the majority was in the mental region $(28.57 \%)$ and lips $(28.57 \%)$, followed by oral mucosa $(14.28 \%)$ and face $(14.28 \%)$, tongue $(10.71 \%)$ and others. All injuries were lacerations. The only treatment for these cases was suture of the tissue laceration.

\section{Location of Fractures}

There were 133 fractures in 103 patients treated during the period studied. The site of fractures is presented in Table 3. The mandible was the most frequently fractured bone, accounting for 73 fractures in 50 patients $(54.88 \%$ ), followed by the alveolar process $(32.33 \%)$, the zygomatic and orbit $(7.59 \%)$, nasal fractures $(2.95 \%)$ and maxilla $(2.25 \%)$.

TABLE 2- Analysis of etiologic factors of maxillofacial fractures

\begin{tabular}{lcc}
\hline Cause & Number of cases & (\%) \\
\hline Falls & 39 & 37.87 \\
Bicycle/motorcycle & 22 & 21.36 \\
Fight/assault & 15 & 12.56 \\
Sports & 08 & 7.76 \\
Road traffic accidents & 16 & 5.54 \\
Others & 03 & 2.91 \\
Total & 103 & 100 \\
\hline
\end{tabular}

TABLE 1- Classification of maxillofacial fractures

\begin{tabular}{|c|c|c|c|}
\hline Site & Single, multiple & Number of fractures & $(\%)$ \\
\hline Maxilla & Le Fort I, Le Fort II, Le Fort III & 03 & 2.25 \\
\hline Mandible & $\begin{array}{l}\text { Condyle, coronoid, ramus, angle, body, } \\
\text { parasymphysis, symphysis and combined }\end{array}$ & 73 & 54.88 \\
\hline Zygoma/Orbits & & 10 & 7.59 \\
\hline Dentoalveolar & Maxilla, mandible and combined & 43 & 32.33 \\
\hline Others & $\begin{array}{l}\text { Nasal, NOE (naso-orbital-ethmoid) } \\
\text { and miscellaneous }\end{array}$ & 04 & 2.95 \\
\hline
\end{tabular}


TABLE 3- Location of the mandibular fractures and treatment

\begin{tabular}{lccccc}
\hline $\begin{array}{c}\text { Location of } \\
\text { mandibular fracture }\end{array}$ & Number & Non-operatively & Operatively & \multicolumn{2}{c}{ Fixation system } \\
$\mathbf{a}$ & & 0 & - \\
\hline Condylar Neck & 34 & 34 & 10 & - \\
Parasymphysis & 13 & 03 & 08 & 05 & 05 \\
Angle & 12 & 04 & 04 & 04 \\
Body & 09 & 05 & 03 & 01 \\
Symphysis & 05 & 02 & 25 & 02 \\
TOTAL & 73 & 48 & 17 & 08 \\
\hline
\end{tabular}

a: Transosseous wiring. b: miniplate osteosynthesis.

The most common site of mandibular fracture was the condylar neck $(46,58 \%)$, followed by the parasymphysis $(17.8 \%)$, angle $(16.44 \%)$, body $(12.33 \%)$ and symphysis $(6,85 \%)$. No fracture involved the coronoid process. A considerable proportion of the patients had more than one mandibular fracture $(36 \%)$ and a small proportion had more than two mandibular fractures $(10 \%)$.

Of all types of fractures, $32.33 \%$ was located in alveolar process. The distribution of alveolar bone fractures was 33 cases $(76.7 \%)$ in the maxilla and 10 cases $(23.3 \%)$ in the mandible. Maxillary fractures $(2.25 \%)$ were at a level of Le Fort I (one case), Le Fort II (one case) and Le Fort III (one case). There was no fracture in midline separation.

\section{Treatment}

Of 73 mandibular fractures, $65.75 \%$ were treated nonoperatively. In these cases, the treatment of choice was analgesics, a liquid-to-soft diet and observation. The occlusion was maintained satisfactorily in all cases. Several methods of reduction and fixation were used in the treatment of some fractures in mandible. Some fractures in mandible $(34.25 \%)$ were treated with open reduction and fixation with transosseous wiring or internal fixation with miniplate osteosynteshis. There is no surgical treatment of condylar fractures. The fractures and their treatment of choice are shown in Table 3.

There were three middle-third-fractures in children, which were treated by the same methods used in adults. One case was treated with circumzygomatic wiring. Other case was treated with intermaxillary fixation plus transosseous wiring. The late case was treated with combined treatment (circumzygomatic wiring, intermaxillary fixation and transosseous wiring).

Of all fractures of the alveolar process, $23.3 \%$ was located in the mandible. The treatment of choice was interdental wiring $(70 \%)$ followed by suture of the bone fragment $(20 \%)$ and others $(10 \%)$. In the maxilla, the treatment was interdental wiring $(57.5 \%)$, followed by suture of the bone fragment $(33.34 \%)$ and others, like combined treatment and splints.

Zygomatic and orbit and nasal fractures were treated only operatively. In most patients, the bone fragment was fixed with transosseous wiring $(80 \%)$. Internal fixation with mini-plate osteosynthesis was performed in $10 \%$ of cases. In the other cases, the treatment was not identified in the medical records.

Complications associated with all procedures will be discussed in a further research.

\section{DISCUSSION}

Numerous reports on pediatric facial trauma patients have published. Pediatric maxillofacial fractures comprised $29.42 \%$ of the population sustaining maxillofacial fracture in our series. Previous reports have stated that the incidence varies between $3.7 \%{ }^{7}$ to $14.7 \%{ }^{11}$ of all maxillofacial fracture. Compared to these reports, a higher percentage was recognized in our department. This divergence may be explained because our service was, during some time, one of the few hospitals treating emergency pediatric cases in the city. The gender distribution was similar to that reported elsewhere, with a preponderance of boys to girls. The predominance of injured males in the 13-18-year-old age group is consistent with the findings of previously published works, with male-to-female ratios ranging from $2: 1$ to $6: 1^{1,3,9}$. In this study, the male-to-female ratio was $1.7: 1$, which was a higher incidence rate of fractures in females when we compared to other case series. In fact, there is a trend of approximating the male to female ratio because boys and girls are becoming more and more engaged in the same activities.

The peak age incidence of facial fractures is difficult to compare, since the available studies have used different upper age limits for their samples. In this study, the peak incidence was at age 10.61. Another study showed similar mean ages 9 . It is speculated that this age related peak are attributable to the development status of facial structures, especially teeth and sinus, and to the habits of children and adolescents.

Published data from different studies on the etiology tend to vary from one country to another, perhaps because of the differences in social, cultural and environmental factors. Accidental falls were found to be the most common cause 
of maxillofacial fractures in children as shown in many studies ${ }^{4,5,9,12}$. This corresponded to the findings of this study that accidental falls were responsible for $37.87 \%$ of maxillofacial fractures. This fact can be attributed to children's underdeveloped motor skills and coordination, mainly those aged 0 to 6 years. Other studies ${ }^{3,8}$ confirmed that motor vehicle accidents were a leading cause of facial fractures, and in our study, they caused $15.54 \%$ of the injuries. Another study ${ }^{2}$ found that violence is still a leading cause $(16.7 \%)$. In our case series, fight and physical assaults correspond to $14.56 \%$. One reason for this difference is that at time of the study, the city of Curitiba presented a low criminality rate when compared to other Brazilian cities.

The monthly distribution of injuries was almost equal along the experimental period, which may be explained by the weather of our city. Brazil is a tropical country and, in all seasons, there is no drastic temperature change in most regions.

Some authors ${ }^{2,6,9}$ have reported that mandibular fracture accounted for most facial bone fractures encountered in children. This was also shown in our study. Mandibular fractures were found to account for $54.88 \%$ of facial fractures. It is important to note that other authors reported that fracture of the nasal skeleton accounted for most facial bone fractures encountered in children ${ }^{1,12}$. In the Hospital, nasal fractures are mainly waited for plastic surgeons.

Condylar fractures were the most common site of mandibular fracture with $46.58 \%$, as report by many authors $3,6,7,9$. The higher incidence of condylar fractures in children than adults may be explained by the higher proportion of medullary bone with only a thin rim of cortex ${ }^{6}$. Our series revealed that parasymphyseal fractures were the second most common site. It is different from the findings of other authors that showed mandibular angle were the second most common location $^{6,8}$. This difference can be explained because of accidental falls is the most present etiology in our study and, generally, when children fall, the symphyseal region is the first place to be injured. The impact is first dissipated to the condyle and then to the parasymphyseal region.

Fractures of the alveolar process are common; corresponded to $32.33 \%$ of the cases in our study and were also frequent in other investigations ${ }^{6}$. Our results show a decrease of alveolar fractures with age. It may reflect the growth of the facial skeleton and development of casual activities with care and motor skills.

Three maxillary fractures were recorded in our study. This low percentage is in agreement with the findings of other authors ${ }^{7}$. This may be attributed to the fact that the midface is the most protected area in children because of its retrusive position relative to the prominent calvaria. Mandibular fractures in children were treated according to the protocol reported in the literature. The condylar fractures were treated with close reduction. All forms of wiring and arch bars were used for fixation. The use of miniplate osteosynthesis has increased considerably. This method is used only in few situations in our Hospital because, at time of this study, the Municipal Health System did not supply miniplates for internal rigid fixation.

\section{CONCLUSION}

The outcomes of this study indicate that fractures of the facial skeleton are frequent in Brazilian children and adolescents. Our findings support the view that many factors related to trauma vary from one country to another.

\section{REFERENCES}

1- Anderson PJ. Fractures of the facial skeleton in children. Int J Care Injured. 1995;26:47-50.

2- Bamjee Y, Lownie JF, Cleaton-Jones PE, Lownie MA. Maxillofacial injuries in a group of South Africans under 18 years of age. Br J Oral Maxillofac Surg. 1996;34:298-302.

3- Cossio PI, Galvez FE, Perez JLG, Garcia-Perla A, Guisado JMH. Mandibular fractures in children. Int J Oral Maxillofac Surg. 1994;23:32931 .

4- Gassner R, Tuli T, Hächl O, Moreira R, Ulmer H. Craniomaxillofacial trauma in children: a review of 3.385 cases with 6,060 injuries in 10 years. J Oral Maxillofac Surg. 2004;62:399-407.

5- Haug RH, Foss J. Maxillofacial injuries in the pediatric patient. Oral Surg Oral Med Oral Pathol Oral Radiol Endod. 2000;90:126-34.

6- Iida S, Matsuya T. Paediatric maxillofacial fractures: their aetiological characters and fracture patterns. J Cranio-Maxillofac Surg. 2002;30:23741 .

7- Oji C. Fractures of the facial skeleton in children: a survey of patients under the age of 11 years. J Cranio-Maxillofac Surg. 1998;26:322-5.

8- Prigozen JM, Horswell BB, Flaberty SK, Henderson JM, Graham DA, Armistead LM, et al. All-terrain vehicle-related maxillofacial trauma in the pediatric population. J Oral Maxillofac Surg. 2006;64:1333-7.

9- Qudah MA, Bataineh AB. A retrospective study of selected oral and maxillofacial fractures in a group of Jordanian children. Oral Surg Oral Med Oral Pathol Oral Radiol Endod. 2002;94:310-4.

10- Shaikh ZS, Worrall SF. Epidemiology of facial trauma in a sample of patients aged 1-18 years. Int J Care Injured. 2002;33:669-71.

11- Tanaka N, Uchide N, Suzuki K, Tashiro T, Tomitsuka K, Kimijima Y, et al. Maxillofacial fractures in children. J CranioMaxillofac Surg 1993;21:289-93.

12-Zerfowski M, Bremerich A. Facial trauma in children and adolescents. Clin Oral Invest 1998;2:120-4. 